\title{
Sternocostoclavicular involvement in psoriatic arthritis
}

\section{Toshiyuki Yamamoto}

\author{
Department of Dermatology, Fukushima Medical University, Fukushima, Japan
}

Corresponding author: Prof. Toshiyuki Yamamoto, E-mail: toyamade@fmu.ac.jp

Sir,

The anterior chest wall is the mainly affected region in pustulotic arthro-osteitis (PAO) associated with palmoplantar pustulosis (PPP). By contrast, sternocostoclavicular arthritis is rare in psoriatic arthritis (PsA). We report two cases of Japanese patients with psoriasis that led to the development of arthroosteitis in the anterior chest wall.

Case 1: A 28-year-old female developed chronic scaly erythemas on the occipital scalp and was diagnosed with psoriasis at the age of 16. Furthermore, she had been suffering from joint pain in the anterior chest wall, left shoulder, wrist, and toes for several years. A physical examination revealed keratotic erythematous plaques on the scalp, back, and left elbow (Fig. la). Neither of the palms or soles was involved. The Psoriasis Area and Severity Index (PASI) score was 4.5. Moreover, the anterior chest wall was painful and showed swelling (Fig. 1b). A laboratory examination showed a slight increase in C-reactive protein (CRP) $(1.0 \mathrm{mg} / \mathrm{dL})$; however, rheumatoid factor, antinuclear antibodies, and matrix metalloproteinase-3 were within the normal ranges. Technetium-99 bone scintigraphy revealed increased uptake in the thorax, right wrist, and right fourth toe (Fig. 1c). The patient was treated with topical corticosteroid and oral methotrexate $7.5 \mathrm{mg} /$ week.

Case 2: A 52-year-old female had developed generalized erythema, scales, and tiny superficial pustules, and had been treated on repeated admission in another hospital. The skin conditions had been compounded by a sore throat, fever-up, and joint pain. The patient was treated with etretinate $\left(\right.$ Tigason $^{\mathrm{TM}}{ }^{\text {) }}$ but without improvement and was thus referred to our hospital. A physical examination showed that the ill-defined scaly erythemas had spread and coalesced diffusely with

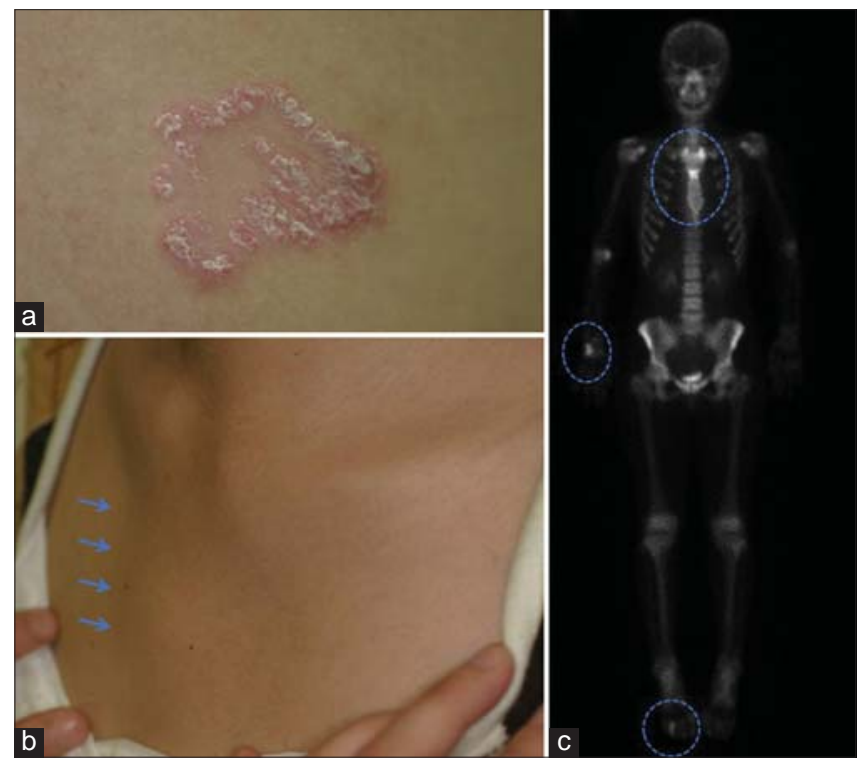

Figure 1: (a) A well-circumscribed scaly erythematous plaque. (b) Swelling of the anterior chest wall (at the arrow). (c) Bone scintigraphy showing increased uptake in the sternocostoclavicular areas, right wrist, and right toes.

superficial tiny pustules on the trunk and extremities (Fig. 2a). A histological examination revealed a Kogoj's spongiform abscess in the epidermis with perivascular inflammatory cell infiltration in the upper dermis. A laboratory examination showed increased levels of white blood cell count $(13,600 / \mu \mathrm{L})$ and CRP $(5.6 \mathrm{mg} / \mathrm{dL})$, whereas renal and liver functions were normal. Therapy with methotrexate $30 \mathrm{mg} /$ week was started and then tapered with the improvement of skin lesions. The joint pain, however, was not completely controlled and the right clavicle showed a marked swelling. Technetium-99 bone scintigraphy revealed increased uptake in the thorax, right wrist, and right fourth toe (Fig. 2b).

Psoriasis and PPP share several similarities, although PPP is considered an entity distinct from psoriasis [1].

\footnotetext{
How to cite this article: Yamamoto T. Sternocostoclavicular involvement in psoriatic arthritis. Our Dermatol Online. 2020;11(4):436-437.

DOI: 10.7241/ourd.20204.33
} 


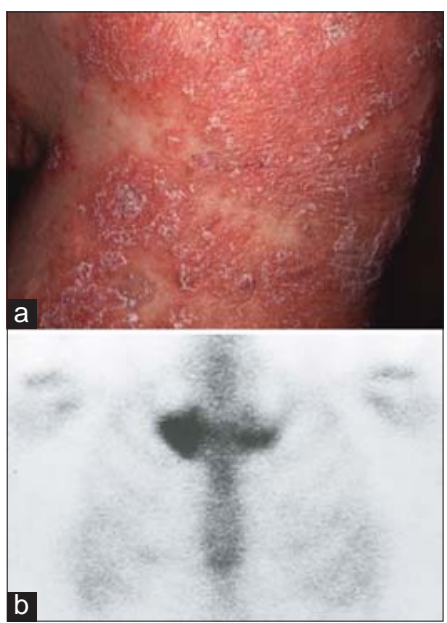

Figure 2: (a) A number of scaly erythemas with superficial tiny pustules on the trunk. (b) Bone scintigraphy showing increased uptake in the right clavicle.

An examination of 44 patients with PAO by bone scintigraphy revealed that the increased uptake of technetium was most frequently observed in the sternocostoclavicular region, which accounted for $82 \%$ (36/44) of cases [2]. As for the joint manifestation, enthesitis is the primary event of both PsA and PAO. PsA involves both peripheral and axial joints, with a predominance of peripheral involvement (60\%) [3]. By contrast, PAO affects the anterior chest wall in the majority of cases, with less involvement of peripheral joints [1]. A recent retrospective study examined 104 cases of PsA, among which axial disease accounted for $43.2 \%$ (45/104) of cases [4]. Three cases of anterior chest wall involvement were described, but only one was psoriasis while the rest were cases of palmoplantar psoriasis and PPP.

In this report, we present two cases of plaque-type psoriasis vulgaris and generalized pustular psoriasis without a family history of psoriasis or PPP. Neither palms nor soles were involved, and neither patients had severe acne. In case 1, arthralgia was observed in not only the anterior chest wall but also the peripheral joints, whereas, in case 2 , the patient complained of joint pain in the right clavicular region only. In our institute, we have had more than 80 cases of PsA in over ten years, but no other cases developed arthritis on the anterior chest walls. Although we have had a number of Japanese patients with PAO [5], sternocostoclavicular arthritis is rare in Japanese patients with PsA. In conclusion, these two cases suggest a close relationship between PsA and PAO.

\section{Consent}

The examination of the patient was conducted according to the principles of the Declaration of Helsinki.

The authors certify that they have obtained all appropriate patient consent forms, in which the patients gave their consent for images and other clinical information to be included in the journal. The patients understand that their names and initials will not be published and due effort will be made to conceal their identity, but that anonymity cannot be guaranteed.

\section{REFERENCES}

1. Yamamoto T. Clinical characteristics of Japanese patients with palmoplantar pustulosis. Clin Drug Invest. 2019;39:241-52.

2. Hiraiwa T, Yamamoto T. Bone scintigraphy analysis of 44 cases of pustulotic arthro-osteitis associated with palmoplantar pustulosis. J Dermatol. 2019;46:e122-3.

3. Kose R, Senturk T, Sargin G, Cildag S, Kara Y. Pustulotic arthroosteitis (Sonozaki syndrome): a case report and review of literature. Eurasian J Med. 2018;50:53-5.

4. Fragoulis GE, Evangelatos G, Konsta M, Iliopoulos A. Anterior chest wall involvement in psoriatic arthritis: a forgotten entity? Rheumatology. 2020;keaa145.

5. Yamamoto T, Hiraiwa T, Tobita R, Hirano H, Masuda-Kuroki K, Ishii M, et al. Characteristics of Japanese patients with pustulotic arthro-osteitis associated with palmoplantar pustulosis: a multicenter study. Int J Dermatol. 2020;59:441-4.

Copyright by Toshiyuki Yamamoto. This is an open-access article distributed under the terms of the Creative Commons Attribution License, which permits unrestricted use, distribution, and reproduction in any medium, provided the original author and source are credited.

Source of Support: Nil, Conflict of Interest: None declared. 